\title{
A ARTIFICIALIZAÇÃO E A NEGAÇÃO DA VIDA HUMANA: O (DES)COMPASSO ENTRE A TECNOLOGIA E O DIREITO DE VIVER HUMANAMENTE
}

\author{
THE ARTIFICIALIZATION AND THE DENIAL OF HUMAN \\ LIFE: THE (MIS)MATCH BETWEEN TECHNOLOGY AND \\ THE RIGHT TO LIVE HUMANALLY
}

\begin{abstract}
RESUMO: O trabalho aborda, com base no método hipotético-dedutivo, mediante pesquisa em materiais físicos e digitais, a relação entre as descobertas da tecnologia médica e a vida humana. A investigação centrase no seguinte problema: em que medida, com suporte nas discussões de dignidade, o desenvolvimento tecnológico tem o condão de interferir, positiva ou negativamente, na vida humana a ponto de artificializá-la? Os objetivos são analisar, inicialmente, a imbricação da vida e da dignidade à luz do direito e da ética e, na sequência, refletir sobre o avanço científico e a possível produção de vida artificial com subsídio em descobertas médicas das últimas décadas e na série britânica Black Mirror. A tecnologia médica evolui sobremaneira desde o século XX e se apresenta como um rompimento da pretérita busca por conhecer o corpo para, agora, almejar criá-lo, talvez, em laboratório. O resultado é, de um lado, o favorecimento das descobertas clínicas para o cuidado da vida, mas, de outro, o fomento à objetificação do ser humano. Por isso, com fundamento na ideia de dignidade humana, a bioética e o biodireito foram áreas técnicocientíficas criadas recentemente para a discussão.
\end{abstract}

Palavras-chave: Artificialização. Ciência. Dignidade. Tecnologia. Vida humana.
ABSTRACT: The paper adresses, based on the hypotheticaldeductive method through research in physical and digital materials, the relationship between the findings of medical technology and human life. The research focuses on the following problem: to what extent, with support in the discussions of dignity, does technological development have the ability to interfere, positively or negatively, in human life to the point of artificializing it? The objectives are to analyze, initially, the imbrication of life and dignity in the light of law and ethics and then to reflect on the scientific advance and the possible production of artificial life with subsidy in medical discoveries of the last decades and in the british series Black Mirror. Medical technology has evolved greatly since the twentieth century and presents itself as a break from the past, the quest to know the body, and now, to seek to create it, perhaps in the laboratory. The result is, on the one hand, the favoring of clinical discoveries for the care of life, but, on the other, the promotion of the objectification of the human being Therefore, based on the idea of human dignity, bioethics and bioright were technical and scientific areas recently created for discussion.

Keywords: Artificialization. Science. Dignity. Technology. Human life.

\footnotetext{
${ }^{1}$ Doutor em Direito Público pela Universidade do Vale do Rio dos Sinos (UNISINOS). Professor do Mestrado em Direitos Humanos da Universidade Regional do Noroeste do Estado do Rio Grande do Sul (UNIJUÍ) e dos Cursos de Graduação em Direito da UNIJUÍ e UNISINOS. Líder do grupo de pesquisa Biopolítica e Direitos Humanos (CNPq).

${ }^{2}$ Mestrando no Programa de Pós-Graduação Stricto Sensu em Direito - Mestrado em Direitos Humanos - da Universidade Regional do Noroeste do Estado do Rio Grande do Sul (UNIJUÍ). Bolsista da Coordenação de Aperfeiçoamento de Pessoal de Nível Superior (CAPES). Bacharel em Direito pela UNIJUÍ. Integrante do Grupo de Pesquisa do CNPq: Biopolítica e Direitos Humanos.
} 


\section{CONSIDERAÇÕES INICIAIS}

A vida é o elemento fundante da pessoa humana e de todos os direitos inerentes ao indivíduo. Trata-se de um direito natural, pela sua própria essência, transformado posteriormente em direito positivado nos documentos legais dos Estados-nação. Hoje, a vida é um direito humano e fundamental constitucionalizado e extensivamente tutelado pelos textos declarativos e jurídicos de abrangência nacional e internacional.

O exercício da vida humana, nas suas variadas relações privadas e públicas, suscitou nos últimos séculos o debate em torno do que se entende como dignidade. A dignidade é uma característica basilar pela qual se almeja condições mínimas para a vivência, por meio, exemplificativamente, de saúde, moradia, educação e segurança. É o bem-estar pessoal, pois, que se objetiva alcançar.

O corpo humano tem sido objeto de estudos científicos há muitos séculos. Os segredos guardados pela natureza levam continuamente pesquisadores a conhecer as nuanças da vida e a entendê-la. A tecnologia no campo médico, diante disso, tem apresentado expressivos resultados, principalmente desde o século $X X$ e erguido um debate jurídico e ético. É o que se problematiza neste trabalho.

A investigação centra-se no seguinte problema: em que medida, com suporte nas discussões de dignidade, o desenvolvimento tecnológico tem o condão de interferir, positiva ou negativamente, na vida humana a ponto de artificializá-la? O debate instala-se com referência às descobertas científicas divulgadas nas últimas décadas e ao futurismo artificial suscitado na série britânica Black Mirror.

A pretensão, com este estudo, fixa-se em discutir, com suporte nos ideais de dignidade, direito e ética, o avanço tecnológico relacionado à medicina e a sua relação com uma eventual objetificação do ser humano, emergindo-se da hipótese de que o crescimento das pesquisas médicas tem incitado a produção de vida em laboratório e a criação mecânica e artificial de partes do corpo, do que pode resultar, por vezes, a artificialização da vida humana.

O artigo encontra-se estruturado em duas seções, que correspondem aos seus objetivos específicos. Na primeira seção, aborda-se o tema da vida e da dignidade humana 
a partir dos aportes teóricos do (bio)direito e da (bio)ética, partindo-se do fato de que, na contemporaneidade, a acepção acerca do que é a vida cerca-se de singularidades, uma vez que os avanços científicos relativizam assuntos que até então pareciam estremes de dúvida, exigindo constantes revisões do conceito de dignidade humana. Na segunda seção, o artigo investiga a temática da artificialização da vida em decorrência dos avanços científicos, notadamente no campo da genética, âmbito no qual, por meio da criação e da intervenção de tecnologias no corpo humano, suscitam-se intensos debates em relação ao direito à vida e ao princípio da dignidade da pessoa humana.

A fim de alcançar aos objetivos propostos, a presente pesquisa utiliza-se do método hipotético-dedutivo, com técnica de pesquisa que consiste na coleta de informações em materiais físicos e digitais, com o fito de subsidiar o arcabouço doutrinário e legal, bem como propiciar o debate acerca da evolução científica e as suas consequências para a vida humana e para a ideia de dignidade.

\section{VIDA, DIGNIDADE, DIREITO E ÉTICA}

A existência humana pressupõe a vida como elemento substancial para todo o agir e acontecer natural e tecnológico da sociedade. A vida torna-se a característica fundante da constituição e realização do ser humano e do desenvolvimento das comunidades. Trata-se de um direito que exige atenção do poder público e necessita de cuidado pessoal para a sua concreta efetivação.

Os gregos, na Antiguidade, diferentemente da concepção atual e ocidentalmente hegemônica, entendiam a vida a partir de duas vertentes. Na análise de Giorgio Agamben (2007, p. 09), havia, de um lado, zoé, e, de outro lado, bíos, os quais significavam, respectivamente, a vida natural ou meramente existencial do indivíduo e a vida qualificada ou abrangida pelo estatuto jurídico-político, ou seja, protegida.

A partir desse marco inicial, ao longo da história da humanidade, a vida da pessoa humana passou por distintas formas de compreensão. Destacam-se, dentro dos limites deste estudo, três conceitos principais, a partir da obra de Pessini e Barchifontaine (2000, p. 67-68): primeiramente, há o conceito metafísico de pessoa elaborado pelos pensadores cristãos na Idade Média, segundo o qual "a razão é constitutiva da personalidade", sendo 
que, na tradição cristã medieval, a racionalidade, dom divino, é o que "define a especificidade do ser humano, ou seja, é a alma racional que nos diferencia de todos os seres vivos". Nesse contexto, "a pessoa tem sempre igual valor em toda sua existência, da concepção à morte."

Em um segundo momento, a fenomenologia desenvolvida no século XX estabelece um conceito mais "dinâmico" de pessoa, partindo da ideia central de relação. O ser humano não configura uma "essência" que é definida $a b$ initio, mas sim um ser relacional, "um tecido de relações". Com isso, "a personalidade vai se construindo com os acontecimentos pessoais e os que nos cercam", sendo que "essas relações são o alicerce da personalidade". Tais relações, quando bem conduzidas e equilibradas, tendem a produzir uma personalidade adulta e equilibrada; caso contrário, tem-se como produto personalidades problemáticas de difícil integração à sociedade. Nessa lógica, “a pessoa, como relação, constrói-se toda inteira, corpo e espírito, no processo relacional e temporal." O elemento divino sai de cena e cede espaço às nossas circunstâncias relacionais (PESSINI; BARCHIFONTAINE, 2000, p. 68).

Por fim, em um terceiro momento, a partir das teorias evolucionistas, "a ontogênese resume a filogênese", de modo que cada ser, nesta concepção, "recapitula os passos da espécie ao longo dos milênios." Nesse sentido, "os elementos genéticos vão se desdobrando, crescendo em perfeição até serem aptos a fazer atos conscientes ou escolhas livres quando o conjunto biológico alcançou maior maturidade." Ao final de um longo itinerário, o ser alcança um grau tal de aperfeiçoamento de seu sistema nervoso que começa a pensar, ter consciência e, a partir delas, tomar decisões. Trata-se do "salto do processo evolutivo determinístico e puramente biológico para o estágio da consciência e da liberdade." (PESSINI; BARCHIFONTAINE, 2000, p. 69).

$\mathrm{Na}$ contemporaneidade a acepção acerca do que é, enfim, a vida, cerca-se de singularidades. Avanços científicos relativizam assuntos que até então pareciam estremes de dúvida. Mesmo assim, a ciência considera difícil conceituar "vida", uma vez que engloba uma variante expressiva de relações, as quais partem dos mais simples seres vivos ao homo sapiens, mas, ao mesmo tempo, tão impossível de ser compreendida. A vida é vista, 
nas palavras de Lynn Margulis e Dorion Sagan (2002, p. 15), como "um eterno enigma", principalmente para os cientistas.

Na mesma linha, James Lovelock (2006, p. 27) pontua que a vida integra uma ampla definição e que, costumeiramente, é compreensível para a comunidade em geral, mas, em contrapartida, não tão facilmente inteligível e entendida pelos estudiosos da área, uma vez que "todos sabem do que se trata, mas poucos, se é que existem, podem explicá-lo [conceito de vida]".

A complexidade do termo vida pode ser vislumbrada a partir de um resgate histórico e filosófico. Ao construir uma definição mediante a análise de diversos teóricos da Antiguidade à Modernidade, Nicola Abbagnano (2007, p. 1000) constrói a conceituação de vida como sendo a "característica que têm certos fenômenos de se produzirem ou se regerem por si mesmos, ou a totalidade de tais fenômenos".

"A espontaneidade com que os seres vivos se movem, se nutrem, crescem, se reproduzem e morrem" é um fenômeno da vida defendida, na concepção de Abbagnano (2007, p. 1001), desde a Antiguidade, a exemplo das teses de Platão e Aristóteles. Já Immanuel Kant, na Modernidade, conforme Abbagnano (2007, p. 1001), considera a vida como a capacidade de agir de acordo com a "faculdade de desejar".

Juridicamente, a vida, conforme Maria Garcia (2010, p. 01), é um bem tutelado desde o instante da concepção, isto é, desde a formação cientificamente comprovada do ser humano. Trata-se do momento em que, pelos viés do direito, o sujeito é resguardado e protegido para o exercício de todos os atos resultantes de sua existência, a exemplo, consoante Garcia (2010, p. 01), das garantias inerentes à saúde, ao trabalho e à liberdade.

O direito elementar para a inscrição jurídica e protecionista no Estado em relação ao ser humano pode ser compreendido à luz da vida. É a circunstância elementar, divina ou natural, a depender da crença religiosa (ou não) que se tenha, que garante a realização diária nas searas pessoal e profissional. É a partir da vida, sob o viés jurídico, que se fecundam todos os demais direitos e garantias legais.

Dada essa importância, o direito à vida é regulado e assegurado em documentos declarativos e normativos proclamados em caráter nacional e internacional, integrando o conjunto básico denominado de direitos humanos e fundamentais. A exemplo disso, a 
Declaração Universal dos Direitos Humanos (1948), em seu artigo 3ำ, professa a vida como um direito de todo indivíduo.

No mesmo sentido, a Declaração Americana dos Direitos e Deveres do Homem (1948) menciona a vida como um direito garantido, indistintamente, a todo ser humano. Ademais, o Pacto Internacional sobre Direitos Civis e Políticos (1966), em seu artigo 6ㅇ, inciso III, proclama que o direito à vida se encontra inerente à pessoa humana; logo, é fruto da condição natural do indivíduo.

O fato é que, hoje, "só conhecemos um homem ou ser humano [...]. Seus direitos estão inscritos numa Declaração universal. Este homem tem uma história que ele partilha com seus semelhantes: os humanos." O fato de esse passado ter começado em um ou outro lugar da África, ou há duzentos mil ou dois milhões de anos, não muda em nada a única afirmação importante: "em matéria de homem, as outras espécies vivas, todas as outras, encontram-se rejeitadas no in-humano." Isso significa que "a espécie humana, marca registrada, única em seu gênero, substituiu todos os modelos que precederam ou acompanharam sua inauguração." (VINCENT, 2011, p. 111).

Sendo um direito intrínseco à natureza humana, a vida compõe os chamados direitos da personalidade, os quais se originam de uma evolução lenta, gradual, histórica e universal, emergentes da própria ideia constituinte do homem. Na atualidade, contudo, em virtude da ascensão da Modernidade e do chamado Estado de Direito, os direitos considerados como naturais foram incorporados, isto é, positivados, nos ordenamentos jurídicos.

Aliás, a garantia da vida está intimamente vinculada à edificação do Estado no modelo contratualista. Segundo Thomas Hobbes (2017, p. 138), os indivíduos, que são maus por natureza, viviam em constante luta pela sobrevivência no Estado natural dada a inexistência de um poder central ordenador da sociedade, razão pela qual o pacto social surgiu pela "preocupação com sua própria conservação e a garantia de uma vida mais feliz".

A construção do Estado civil em detrimento do Estado natural, na visão de JeanJacques Rousseau (2015, p. 20), resulta da soma de forças individuais com o intuito de vencer a resistência, atuar em conjunto e manter a sua conservação. Esse processo, na 
concepção rousseauniana $(2015$, p. 24), produz a passagem de um animal de características estúpidas e limitadas para um homem de caráter inteligente.

Dito isso, pois, a vida almejada com a esfera estatal, integrante do núcleo de direitos da personalidade, analisada sob o manto jurídico, é concebida e definida legalmente, segundo Edilson Pereira Nobre (2000, p. 191), como um direito de natureza extrapatrimonial, absoluto, irrenunciável, intransmissível e imprescritível. Aliam-se a essas características, a generalidade, a impenhorabilidade e a vitaliciedade.

Via de consequência, a vida, por integrar os direitos da personalidade, é oponível erga omnes, de modo a irradiar os seus efeitos à coletividade e impor a todos o dever de respeito. Não obstante, a titularidade desse direito é do ser humano, mas não se Ihe atribui a prerrogativa de cedê-lo a outrem, uma vez que lhe é inerente e, logo, vinculado à sua singularidade.

Nesse aspecto, Carlos Alberto Bittar (1999, p. 67) pontua que o direito à vida tem caráter negativo e inibe qualquer declaração de seu titular que provoque cerceamento do direito, uma vez que não se "pode ceifar a vida humana, por si, ou por outrem, mesmo sob consentimento, porque se entende, universalmente, que o homem não vive apenas para si, mas para cumprir missão própria da sociedade".

Ao resguardar e tutelar direitos básicos e inerentes ao ser humano, todos são titulares desse direito, sem qualquer distinção, haja vista a característica da generalidade. Ainda, por ser imprescritível e vitalício, de acordo com Francisco Amaral (2000, p. 252), não há previsão de lapso temporal para o seu exercício, bem como não se conquistam pelo transcurso do tempo e não cessam em razão do seu não uso.

Desta forma, fruto da formação de um direito positivado dentro de um modelo de Estado que ora se apresenta, a vida é condição assegurada normativamente, de modo extensivo, por diplomas legais de níveis internacional e nacional, inclusive sob o prisma constitucional, como é o caso da determinação contida no artigo 5o, caput, da Constituição Federal brasileira (BRASIL, 1988).

A proteção constitucional da vida significa a sua caracterização como direito fundamental. Os direitos fundamentais são aqueles, na visão de José Joaquim Gomes Canotilho (2010, p. 393), garantidos e definidos em um certo espaço de tempo, o que seria 
afirmar o estabelecimento de determinados direitos em um documento normativo com vigência efetiva na ordenamento jurídico.

A vida, assim, é, ao mesmo tempo, direito fundamental e direito da personalidade. Isso porque, segundo Canotilho (2010, p. 396), embora alguns direitos - políticos e de prestações - não sejam intrínsecos ao ser, continuamente, dada a vinculação dos estatutos jurídico-negativo e a noção "de um direito geral de personalidade como 'direito à pessoa ser e à pessoa devir'", os direitos fundamentais são considerados direitos da personalidade e vice-versa.

A par disso, mas não somente sob o comando constitucional, e, sim, em relação ao mundo jurídico, como bem assinala José Afonso Silva (1993, p. 182), tem-se como perceptível que o direito à vida "constitui a fonte primária de todos os outros bens jurídicos". É evidente, pois, que inexistiria fundamento para a garantia dos demais direitos, como a liberdade, a moradia e a expressão, por exemplo, se não houvesse a vida.

Nesse sentido, a vida é elemento pressuposto da existência da pessoa humana. Por isso, Luís Roberto Barroso (2014, p. 406) lembra que “[...] é a partir do nascimento com vida que surge a pessoa humana, com aptidão para tornar-se sujeito de direitos e deveres", sem prejuízo da lei resguardar, desde a concepção, os direitos do nascituro, isto é, o ser humano já concebido, mas ainda não nascido.

A ideia configurativa dos direitos da personalidade, nos quais se inclui a vida, consiste, pois, em oportunizar condições básicas para a existência humana. A pretensão é de oferecer, por meio de um sistema jurídico, a possibilidade de que todos encontrem realização e felicidade nos âmbitos pessoal e profissional com o amparo, também, do Estado, justamente por uma legislação que direcione a esse desiderato.

A partir disso, emerge-se a discussão acerca da dignidade da pessoa humana. No que toca ao direito à vida, tem-se a indagação: o que é viver dignamente? A consagração de direitos, enraizados no intento de promover o respeito à essência formadora do indivíduo, tem na dignidade o fundamento do ordenamento jurídico, embasando juristas e legisladores nas confrontações e decisões legislativas.

O sustentáculo de todo o emaranhado legislativo brasileiro está previsto no artigo 1으, inciso III, da Constituição Federal de 1988. No dispositivo legal, declara-se a dignidade 
da pessoa humana como um dos fundamentos da República Federativa do Brasil, ao lado da soberania, da cidadania, dos valores sociais do trabalho e da livre iniciativa e do pluralismo político (BRASIL, 1988).

Um direito fundamental significa a essência do indivíduo. De tal sorte, ser respeitado nesses valores é sentir-se digno como fator imprescindível para a vivência. Nessa seara, Immanuel Kant (2005, p. 243), ao contribuir para a concepção universal e primordial de dignidade, considera o homem como um fim, e não um meio, em si mesmo, pois ele está acima de qualquer conotação pecuniária.

A dignidade humana consiste, a partir do avanço histórico, como um valor fundamental transformado em princípio jurídico da ordem constitucional e, consequentemente, refletido em todos os diplomas legais, pois este mandamento, segundo Barroso (2014, p. 296), serve "tanto como justificação moral quanto como fundamento normativo para os direitos fundamentais."

Na mesma linha de raciocínio, mediante uma definição abrangente e vinculada à noção existencial do indivíduo na sociedade e, logo, inserido em relações com seus pares, Ingo Wolfgang Sarlet (2001, p. 60) conceitua a dignidade como

\begin{abstract}
a qualidade intrínseca e distintiva de cada ser humano que o faz merecedor do mesmo respeito e consideração por parte do Estado e da comunidade, implicando, neste sentido, um complexo de direitos e deveres fundamentais que assegurem a pessoa tanto contra todos e qualquer ato de cunho degradante e desumano, como venham a lhe garantir as condições existenciais mínimas para uma vida saudável, além de propiciar e promover sua participação ativa e coresponsável nos destinos da própria existência e da vida em comunhão com os demais seres humanos.
\end{abstract}

Desse modo, o exercício do direito à vida e as suas implicações e nuanças jurídicas e fáticas, por vezes, inclusive, na busca pela realização da noção que se tem por dignidade da pessoa humana, ensejam diversos debates. É o que, à vista do exposto, se analisa no que se refere às intervenções tecnológicas na vida humana e às suas confrontações com os ramos do Direito e da Ética.

A vida, como visto, é um bem jurídico expressivamente tutelado pelo Direito. Os diplomas legais asseguram uma proteção extensiva e rígida com a vida humana e, consequentemente, com todos os elementos físicos, químicos e psíquicos que formam o 
corpo. As intervenções médicas encontram previsão legal e, em regra, são sujeitas a diversos critérios e procedimentos.

A título exemplificativo, o Código Civil brasileiro, em seu artigo 15, preceitua que "ninguém pode ser constrangido a submeter-se, com risco de vida, a tratamento médico ou a intervenção cirúrgica" (BRASIL, 2002). Tal disposição legal demonstra uma veia substancial de proteção estatal da vida, uma vez que obsta a ação médica no corpo humano caso possa resultar em dano à vida - considerada, aliás, como direito humano elementar.

A busca pela vida saudável é inerente ao direito aqui discutido. A Constituição Federal, inclusive, em seus artigos 6o e 196, firma que a saúde é um direito social assegurado a todos e de dever do Estado, garantido por intermédio de políticas sociais e econômicas focadas na redução do risco de patologias, assim como ao acesso universal e igualitário às ações e aos serviços para sua promoção, proteção e recuperação (BRASIL, 1988).

Verifica-se, a partir disso, que há uma forte proteção legal em defesa da vida humana. O ordenamento jurídico obsta até mesmo a livre disposição do corpo pela pessoa. É o que se lê no artigo 13 do Código Civil: "Salvo por exigência médica, é defeso o ato de disposição do próprio corpo, quando importar diminuição permanente da integridade física, ou contrariar os bons costumes" (BRASIL, 2002).

A par do embate entre disposição do corpo e dignidade, José Alfredo de Oliveira Baracho (2006, p. 01) assevera que todos os indivíduos têm assegurado a respeitabilidade à dignidade e aos direitos. A dignidade, na concepção de Baracho (2006, p. 01), exige que os sujeitos não possam ser restringidos aos fatores característicos da sua genética, mas, sim, atentar para o respeito à sua singularidade e, ao mesmo tempo, diversidade.

A instituição estatal e organismos internacionais emanaram, principalmente a partir da segunda metade do século $X X$, documentos inibidores de disposição do corpo, a exemplo da Declaração Universal sobre o Genoma Humano e os Direitos Humanos (1997). À luz desta Declaração, reconhece-se que "o genoma humano constitui a base da unidade fundamental de todos os membros da família humana bem como de sua inerente dignidade e diversidade", sendo que, "num sentido simbólico, é o patrimônio da 
humanidade" (artigo 1). Ainda, de acordo com a Declaração da UNESCO, o genoma humano, naturalmente, "está sujeito a mutações", uma vez que "contém potencialidades expressadas de formas diversas conforme o ambiente natural e social de cada indivíduo, incluindo seu estado de saúde, condições de vida, nutrição e educação" (artigo 3), e, "em seu estado natural não deve ser objeto de transações financeiras" (artigo 4) (UNESCO, 2001).

Diante disso, as situações enquadradas em hipótese de violação do corpo humano natural mediante a intervenção da tecnologia e do avanço científico chocam-se, por vezes, com mandamentos legais e éticos. Foi essa colisão de interesses que promoveu a inauguração de novas áreas de estudos especificamente destinadas a investigar a relação, entre outras, das ciências médicas, jurídicas e éticas.

O risco de objetificação do ser humano, transformando-o em mera coisa, objeto, instrumento, foi o estopim para o debate sobre o direito à vida e as suas implicações jurídicas e éticas no que toca às pesquisas genéticas. De acordo com Fukuyama $(2003, p$. 95) "o espectro da eugenia - isto é, a reprodução deliberada de pessoas com certos traços hereditários escolhidos - tem pairado sobre todo o campo da genética". Com efeito, "a engenharia genética reintroduz diretamente a questão da eugenia", mas não nos moldes da experiência nazista, por exemplo, mas a partir de uma perspectiva mais soft, que leva à "possibilidade de uma eugenia mais delicada, mais gentil, que esvaziará a palavra de parte do horror a que está tradicionalmente associada." (FUKUYAMA, 2003, p. 97). Fundaram-se, assim, principalmente a partir desses espectros que ainda rondam as inovações científicas sobre o domínio da vida humana, a bioética e o biodireito, isto é, ramos especializados das ciências para o estudo da vida e a repercussão das investigações da medicina.

São justamente os horrores relacionados à eugenia durante a Segunda Guerra Mundial que são repudiados pelo denominado Código de Nuremberg - documento internacional que estabelece um conjunto de princípios de essência ética a serem observados nas experiências com seres humanos. O princípio básico estabelecido pelo referido Código - que inspirou a disposição dos arts. 13 e 15 do Código Civil brasileiro acima referidos - reside na exigência de que a experimentação médica somente seja realizada em pacientes humanos com o seu consentimento (artigo 1), salientando-se, 
outrossim, que qualquer experimento "deve ser conduzido de maneira a evitar todo sofrimento e danos desnecessários, quer físicos, quer mentais" (artigo 6) (CÓDIGO DE NUREMBERG, 1947).

Um parâmetro ético, para além das discussões sobre a fundamentação ética sob contornos vinculados à natureza humana ou à construção social, vem sendo trabalhado acerca dos avanços da ciência sobre a vida - ou corpo - humana. A conformação fundadora e intrínseca da bioética é analisada por Vítor Coutinho (2007, p. 156):

O núcleo da questão bioética é precisamente a procura de um equilíbrio entre o saber e a consciência, entre as possibilidades das ciências e técnicas biomédicas e os limites decorrentes de uma reflexão antropológica e ética. A bioética é, precisamente, fruto de uma tensão entre as possibilidades técnicas, o saber e as capacidades, e a possibilidade moral, o dever ou os critérios éticos de aplicação (Ciência e Cons-ciência).

O equilíbrio entre o desenvolvimento das pesquisas científicas e a manutenção dos valores éticos e morais concebidos socialmente é, pois, o enfoque da bioética. A ética, consoante Guy Durand (2007, p. 83), consiste em reflexão e questionamento em torno de exigências de respeito e promoção da pessoa balizadas não em um conjunto de regras, mas, sim, em valores e princípios.

A par disso, os frutos do trabalho realizado pelos cientistas levantaram debates junto à sociedade no tocante aos valores e aos princípios individuais e sociais. Isso promoveu a construção da bioética, que, segundo Cláudio Cohen (2008, p. 01), “é um dos tantos fenômenos criados pela cultura para lidar com a complexa combinação de uma revolução científica, e da crise de valores advinda das transformações sociais profundas". De acordo com Pessini e Barchifontaine (2000, p. 32) a bioética, mesmo abarcando a ética médica, não se resume a ela, pois possui quatro aspectos importantes: a) ela compreende também problemas relacionados aos valores próprios de todas as profissões da área da saúde e afins; b) ela se aplica às investigações biomédicas e do comportamento independentemente de influírem ou não diretamente na terapêutica; c) ela envolve uma gama de questões sociais, relacionadas com a saúde ocupacional e internacional, com a ética do controle de natalidade, dentre outras; d) ela ultrapassa a preocupação com a vida e a saúde humanas, compreendendo também questões relativas à vida animal e vegetal, a exemplo dos experimentos em animais e demandas ambientais conflitivas. 
Para Benatar (2003, p. 26) a bioética pode ser definida como a "ética relativa a todos os aspectos da vida", tornando-se ainda mais importante em uma época na qual a biotecnologia genética, as ameaças decorrentes de novas doenças infecciosas e a degradação ambiental se apresentam, ao lado do crescimento das tecnologias de prolongamento da vida.

Ao lado da bioética, e essencialmente resultante desta, há o delineamento do biodireito. Esta área representa a introdução no ordenamento jurídico das discussões e preocupações éticas no que tange às interferências científicas na vida natural. Nesse sentido, Fernanda Schaefer Rivabem (2017, p. 286) afirma que "o biodireito é a manifestação jurídica da bioética".

Como assevera Fukuyama (2003, p. 115-116), "direitos são a base de nossa ordem política democrática liberal e um conceito-chave para o pensamento contemporâneo sobre questões morais e éticas." Desse modo, uma discussão que se pretende séria acerca dos direitos humanos "deve se fundar, em última análise, em alguma compreensão dos fins ou propósitos humanos." Estes, por sua vez, "repousam sempre sobre uma concepção de natureza humana." Nesse passo, quanto mais a ciência avança para desvelar a natureza humana, "mais implicações há para os direitos humanos e, portanto, para o planejamento de instituições e políticas públicas que os protejam."

O biodireito, pois, diz respeito à busca protecionista dos direitos humanos ${ }^{3}$, ou fundamentais, da dignidade da pessoa humana e da privacidade individual. Nessa seara, Daury Cesar Fabriz (2003, p. 288) assevera que o surgimento de um ramo específico do direito alinhado à vida representa a passagem do discurso ético, consubstanciado pela bioética, para a ordem jurídica materializada nos direitos humanos.

\footnotetext{
${ }^{3}$ Salienta-se, aqui, a crítica de Fukuyama (2003, p. 123) à abordagem puramente positivista-universalista dos direitos humanos: "o problema, como qualquer defensor dos direitos humanos aprende na prática, se não na teoria, é que não há direitos positivos que sejam também universais. Quando grupos de direitos humanos ocidentais criticam o governo chinês por prender dissidentes políticos, ele responde que, para a sua sociedade, direitos coletivos e sociais suplantam direitos individuais. A ênfase das organizações ocidentais em direitos políticos individuais não expressa uma aspiração universal, refletindo antes os vieses ocidentais (ou talvez cristãos) dos próprios grupos de defesa dos direitos humanos. O defensor ocidental dos direitos humanos poderia replicar que o governo chinês não seguiu o procedimento correto, porquanto não consultou sua própria população de uma maneira democrática. Mas se não há quaisquer padrões universais para o comportamento político, quem pode dizer qual é o procedimento correto? E que tem a dizer um defensor de abordagem positivista [...] diante de uma outra sociedade, culturalmente diferente, que segue os procedimentos corretos e, no entanto, promove uma prática abominável como a sati, a escravidão ou a castração das mulheres? A resposta é que não há resposta possível, uma vez que foi declarado desde o início que não há padrões transcendentes para a determinação do certo e do errado além do que qualquer cultura declare ser um direito."
} 
A inovação tecnológica no campo médico deve - ou deveria -, portanto, atender aos ditames éticos e legais, fomentando as pesquisas que caminhem para a melhoria da qualidade de vida humana e inibindo as investigações que possam causar a transgressão da natureza do humano para a artificialização do ser, sob pena de infringir os mandamentos inerentes à bioética e ao biodireito.

\section{CIÊNCIA, TECNOLOGIA E PRODUÇÃO DE VIDA ARTIFICIAL}

O campo genético, por meio da criação e da intervenção de tecnologias no corpo humano, tem surgido como debate necessário e intenso quando confrontado com o direito à vida e o princípio da dignidade da pessoa humana. As discussões sobre a temática dividem-se entre o avanço da medicina a favor da saúde e as experiências científicas de mera artificialização da vida.

O ponto nevrálgico da discussão situa-se na impossibilidade prévia de conhecer as consequências das pesquisas e experiências científicas, razão pela qual, conforme Carolina Dantas Figueiredo (2012, p. 204), "sejam quais forem os resultados que determinadas tecnologias podem alcançar, as incertezas provocadas por seu desenvolvimento implicam ansiedade e temor".

A ansiedade e o temor - sentimentos presentes, por vezes, tanto na sociedade científica quanto na comunidade em geral - emergiram na segunda metade do século XX quando, de acordo com Vítor Coutinho (2007, p. 157), as ciências positivas deixaram de lado o status de inocência originária e resultaram na transgressão de suas implicações nas fronteiras do que se tinha como imediato e previsível.

Como destaca Fukuyama (2003, p. 189), dentre as novas tecnologias, algumas são assustadoras desde o início, criando “imediatamente a opinião consensual de que é necessário estabelecer controles políticos sobre seu desenvolvimento e uso", a exemplo das armas nucleares. Por outro lado, há tecnologias que são consideradas mais benignas, razão pela qual são pouco sujeitas a regulação, a exemplo da tecnologia da informação. As biotecnologias, neste contexto, estão situadas em "algum ponto entre os dois extremos": de fato, os alimentos transgênicos e a engenharia genética humana, por exemplo, perturbam muito mais do que as tecnologias da informação; por outro lado, elas 
prometem benefícios importantes para a saúde e o bem-estar da humanidade, de modo que, "diante de um avanço como a capacidade de curar uma criança de fibrose cística ou diabetes, as pessoas têm dificuldade em justificar por que seu receio da biotecnologia deveria se interpor no caminho do progresso." Nesse sentido, "a ameaça real da biotecnologia é muito mais sutil, e por isso de ponderação mais difícil em qualquer cálculo utilitário."

Isso fica bastante evidente a partir da perspectiva histórica: a medicina apresentou um significativo avanço, consoante Baracho (2006, p. 01), com o desenvolvimento dos antibióticos e do conceito de patologia molecular, em 1936, assim como a descoberta do código genético. Na mesma época, em contrapartida, as experiências genéticas promovidas pelos nazistas, liderados pelo ditador alemão Adolf Hitler, desencadearam medo e terror no mundo. A consequência desse cenário catastrófico foi a instituição, no ano de 1947, do Tribunal de Nuremberg, órgão judicial responsável pelo julgamento dos médicos ligados aos experimentos genéticos - e violadores do direitos humanos promovidos durante a Segunda Guerra Mundial, e a elaboração do já referido Código de Nuremberg, "atualizado" pela Declaração de Helsinque, adotada pela Associação Médica Mundial, em 1964, e que preconiza que "o principal objetivo da pesquisa médica envolvendo seres humanos é compreender as causas, evoluções e efeitos das doenças e melhorar as intervenções preventivas, diagnósticas e terapêuticas", de modo que, "mesmo a melhor intervenção comprovada deve ser continuamente avaliada através de pesquisa no que diz respeito à sua segurança, efetividade, eficiência, acessibilidade e qualidade." (artigo 6) (DECLARAÇÃO DE HELSINQUE, 1964).

Com efeito, com o findar da Segunda Guerra Mundial e, por derradeiro, das atrocidades cometidas pelos nazistas, lideranças mundiais instituíram a Organização das Nações Unidas, em 1945, e elaboraram a Declaração Universal dos Direitos Humanos, em 1948, consagrando um rol expressivo de direitos e garantias fundamentais, tendo como cerne a vida e a dignidade humanas. O sistema global de proteção de Direitos Humanos nasce, assim, como contraponto aos horrores do nazismo.

Não obstante, a preocupação com a atuação de cientistas e um eventual descontrole se fortaleceu no fim do século XX, conforme salienta Paulo Otero (1999, p. 11), 
quando resultados relevantes acerca da reprodução humana foram divulgados, uma vez que, à época, se tratava de uma área minimamente desbravada pela ciência e muitas vezes considerada unicamente de dominação da própria natureza.

Nesse contexto, Débora Gozzo (2015, p. 01) contribui para a discussão ao referir os aspectos positivos que resultaram das descobertas científicas em torno da medicina, mas, também, as nuanças negativas:

Desde a segunda metade do século $X X$, o homem é capaz não só de produzir embriões em laboratório, mas também de mantê-los crioconservados, em temperaturas extremamente baixas, que chegam aos 160 graus Celsius negativos. Esta técnica revolucionária de reprodução sexual, que foi desenvolvida no intuito de auxiliar casais inférteis a terem filhos, acabou por gerar vários problemas, uma vez que possibilita o congelamento de embrião humano, isto é, de um ser humano em potência.

Um dos entraves nessa discussão paira na ideia de se gerar seres humanos perfeitos. Pais e mães, ao submeterem embriões a análises clínicas, poderiam descartar embriões caso não apresentassem a perfeição almejada? Esta indagação é trazida por Gozzo (2015, p. 01) ao mencionar, todavia, que a investigação científica deveria, em tese, estar adstrita ao diagnóstico de eventual doença já detectável no material genético.

Há, dessa forma, um dilema latente entre as pesquisas científicas médicas e o direito à vida humana. Se, de um lado, existe a busca pela melhoria da espécie humana, prevenindo doenças e oportunizando que pais inférteis possam gerar filhos; de outro lado, não menos importante, e sim preocupante, existe o debate em torno da eventual artificialização do ser humano enquanto indivíduo programado e disponível em laboratório.

Isto denota, eventualmente, a intenção do ser humano de livrar-se das suas imperfeições, de forma técnica e mecânica, e, consequentemente, avançar o processo natural de evolução da espécie humana. Nessa visão, Pablo Funes (2001, p. 04, tradução livre) enxerga a discussão da artificialização da vida como uma busca, no cenário da biologia, da "vida como deveria ser", e não da "vida como é".

E é justamente sobre essa ideia futurista, baseada nas luzes científicas refletidas, principalmente, desde o século $\mathrm{XX}$, com expressivos e surpreendentes resultados no campo da medicina, que se vislumbra a medicina ligada à formação de vida em laboratório, evidenciando que a ciência está caminhando para uma realidade 
artificialmente produzida e fundada em experimentos realizados por pesquisadores de diversas regiões do mundo.

Se no século $X X$ as pesquisas médicas estavam pautadas no conhecimento dos mistérios da vida e do corpo; já o século XXI parece, de uma forma mais visionária, estar sendo o palco para uma futura criação de vida humana artificial. Estudos recentes, aliás, apontam para uma fase de rompimento do pretérito viés de conhecer o corpo humano para, agora, vir a criá-lo, talvez, em laboratório.

A hipótese acima descrita, em que pese possa ser vista, inicialmente, como utópica e/ou distante, vem sendo retratada e cultivada no mundo, com ênfase em experimentos divulgados nos últimos anos, como, exemplificativamente, a inauguração da biologia sintética, uma criação do Instituto J. Craig Venter, dos Estados Unidos, noticiada, recentemente, pela Revista Superinteressante (2016, p. 01):

A maior descoberta da humanidade desde o fogo. A invenção mais importante (e mais controversa) desde a criação da bomba atômica. $O$ início de uma nova era de prosperidade, saúde e desenvolvimento tecnológico para o homem - ou o começo de sua destruição. Foi assim que jornalistas, cientistas, filósofos e acadêmicos em geral receberam a proeza anunciada pelo geneticista Craig Venter: a criação em laboratório de uma forma de vida sintética.

Trata-se de uma versão artificial da Mycoplasma mycoides, que é uma bactéria conhecida por provocar doenças em bois. A criação científica da vida sintética refere-se, pois, ao primeiro organismo vivo da Terra, produzido artificialmente, a funcionar como genoma, uma vez que o seu código genético, isto é, o DNA, foi construído em laboratório com base em um arquivo digital.

Será esse o primeiro ou, ao menos, o mais relevante passo inicial para uma futura produção de vida "humana" em laboratório? A interferência da tecnologia, por meio de pesquisas promovidas, principalmente, em universidades, tem gerado discussões excessivas acerca da possível retirada de "humanidade" do homem, considerado sob o plano natural, e a sua derradeira artificialização como mero resultado de experiências.

Com a presente invenção, entre tantas outras já divulgadas, traz-se a discussão sobre a utilização da tecnologia como instrumento que caminha em compasso, ou não, com o direito de viver humanamente. O avanço científico, pela artificialização da vida, 
pode provocar melhoras substanciais em diversos aspectos, mas, de outra banda, tem o condão de retirar a "humanidade" natural e essencial do ser humano.

É, aliás, com base nas criações e nas aspirações médicas que Maria Garcia (2010, p. 01, grifos da autora), refletindo sobre a conjuntura científica atual, menciona que, "até agora, o homem dominou a natureza, do seu modo, com um poder de que se autointitulou, originado dele mesmo - e pretende-se, doravante, dominar o próprio corpo humano [...]". Trata-se de um paradoxo do mundo contemporâneo.

Na mesma direção, considerando os possíveis resultados da crescente interferência das descobertas tecnológicas científicas na chamada vida natural, Francis Fukuyama (2003) dispõe que a mais expressiva ameaça apresentada pela biotecnologia contemporânea diz respeito à mutação da natureza humana e, consequentemente, à criação de um estágio pós-humano da história. A expectativa, positiva ou não, do denominado futuro póshumano é trazida por Vítor Coutinho (2007, p. 162):

Num futuro pós-humano, o corpo torna-se irrelevante, deixa de ser expressão da identidade individual. Torna-se indiferente a estrutura que serve de suporte às funções de cada indivíduo, sejam elas ao nível de uma artificialização da inteligência, de optimização de funções orgânicas, ou controlo emotivo.

A vida pós-humana, dessa forma, consiste, segundo Julian Savulescu (2009, p. 214), em seres "evoluídos" ou desenvolvidos por meio de seres humanos, mas expressivamente diversos em todos os seus aspectos, motivo pelo qual deixam de ser humanos. A partir disso, pois, o indivíduo, por sua própria pretensão de aperfeiçoar a sua natureza, deixa de ser essencialmente humano.

Esta visão futurista de um mundo artificial tem ganhado destaque audiovisual e suscitado grandes debates com a série de televisão britânica veiculada pelo serviço de streaming Netflix intitulada de Black Mirror. Trata-se de ficção científica, criada por Charlie Brooker, com o intuito de trazer à tona discussões em relação à sociedade moderna e às consequências da utilização da tecnologia (NETFLIX, 2018).

A retratação do alarmante e surpreendente, mas talvez necessário avanço da tecnologia e, pelo que ora se analisa, da eventual formação de um ser humano artificial, seja de forma corpórea, seja de modo mental, é encontrada basicamente em dois 
episódios da série: The entire history of you, terceiro episódio da primeira temporada, e Be right black, primeiro episódio da segunda temporada.

The entire history of you aborda a implantação de um microchip no corpo humano com o objetivo de gravar as memórias e possibilitar, em áudio e vídeo, que possam ser lembradas a qualquer momento. O episódio marca o uso da tecnologia, por um lado, positivo, pela oportunidade de guardar fatos pretéritos, mas, por outro lado, a sensação de manter sempre presentes acontecimentos que "infernizam" o ser humano.

A ambivalência - benéfica e maléfica - da utilização de tecnologias no corpo, inclusive porque elas rompem com a ideia de naturalidade da vida, é problematizada por Natacha Salomé Lima $(2015$, p. 154) quanto às possíveis consequências do uso do microchip:

[...] vía la implantación de este chip de almacenamiento mnésico, el hombre libera a su cérebro literalmente de su necesidad de recordar. Libera la capacidad de su memoria. Se libera del esfuerzo de tener que recordar, porque ahora la memoria es algo real que está allí a su disposición para cuando así lo requiera. El hombre con este chip mnésico ¿es un hombre mejorado en relación a otro que no tiene el dispositivo implantado? ¿Las personas que poseen una memoria eidética resuelven sus asuntos mejor que las "olvidadizas"? ¿Las posibilidades del olvido nos permiten avanzar o nos condenan a repetir los mismos errores?

O desenvolvimento do campo genético cria, assim, um espaço de ambiguidade no tocante aos seus resultados. Isso porque se tem, de um lado, frutos positivos para a melhoria da qualidade de vida dada a limitação e as deficiências próprias, aliás, da natureza, mas, de outro lado, impõe prejuízos em razão da artificialização da vida e a diferenciação vivencial entre aqueles que têm e aqueles que não têm acesso ao dispositivo inventado.

Be right black, por sua vez, é a externalização de uma história avassaladoramente mais preocupante. O episódio retrata a história de amor de um casal em que, após a morte do homem, a mulher mantém contato com ele por meio de um sistema de software, tomando o homem, inclusive, um corpo artificial, que permanece em companhia, falando e caminhando, com os indivíduos vivos.

A aproximação inicial entre o casal ocorre mediante a utilização de telefone, mas, no decorrer dos dias, a necessidade demonstrada pela personagem de reencontrar o seu amado resulta na criação artificial do corpo do seu - já falecido - amor. A tecnologia, com 
o uso de informações registradas virtualmente, "traz à vida", novamente, o seu marido; porém, as suas atitudes de fala e locomoção retratam um robô, o que, em certa medida, "desumaniza" a relação.

Uma série futurista, visionária ou utópica, Black Mirror leva os telespectadores, pois, a debaterem as pesquisas científicas com fundamento no biodireito e na bioética, também, justamente porque apresenta uma realidade em que o ser humano rompe com as barreiras da vida natural, que até outrora era a única conhecida, para tornar-se, talvez, objeto criado e mantido por sistemas de laboratório científico.

As nuanças desenhadas recentemente pelos avanços científicos, como discorrido anteriormente em relação às pesquisas e à ficção, geram a necessidade de coesão do progresso da ciência com as orientações e determinações permeadas pela bioética e pelo biodireito. A evolução das pesquisas deve respeitar um núcleo basilar legal, formado pelo ordenamento jurídico, e, mesmo sem previsão, os ditames éticos, também.

Tal premissa é consubstancial em virtude da pretensão global de se alcançar e oferecer dignidade aos seres humanos. A par disso, no instante em que o estudo da vida e a intervenção no corpo extrapolam e obstam a concretude dessa almejada dignidade, há que se sopesar até que ponto a produção científica está caminhando em compasso, ou descompasso, com a busca máxima de uma vida digna.

A partir do enfrentamento da ciência e da ética, com discussões centradas na noção de dignidade, Garcia (2010, p. 01) acredita na conciliação futura da dicotomia existente entre ciência e ética como fruto de regras jurídicas, de modo a ser necessária a elaboração e aplicação de normas capazes de harmonizar os embates resultantes do conhecimento científico alinhado, exemplificativamente, à biotecnologia e à engenharia genética.

O debate suscitado pela bioética e pelo biodireito, justificado pelo incremento científico pautado na alteração do paradoxo de conhecer o corpo para agora vir a modificá-lo, é clarividente na visão, consoante Vítor Coutinho (2007, p. 156-157), de que atualmente:

A própria constituição do corpo humano é posta em causa com o desenvolvimento da genética e da possibilidade técnica de alterar o patrimônio genético humano, remodelando, assim, a raça humana. As possíveis alterações do património humano não constituem manipulações acessórias de corpos de indivíduos, mas atingem algo de essencial da espécie humana. 
Desse modo, ultrapassar o limite do razoável, do ético e do legal pode promover aquilo que se analisa neste trabalho como a artificialização do ser humano, uma vez que retira o caráter de "humanidade" da pessoa para transformá-la ou mesmo criá-la em/como objeto da ciência, o que desnatura a essência do ser humano que até pouco tempo era e ainda o é, em tese, visto como criatura à semelhança de Deus.

Não obstante, as pesquisas científicas, de um modo geral, não podem ser censuradas ou aniquiladas pelo poder público ou pela sociedade, haja vista, inclusive, no tocante ao Brasil, a expressa previsão legal de liberdade da atividade científica, sem censura ou licença para esse desiderato, nos termos do artigo 5ำ, inciso IX, da Constituição Federal de 1988. Sem prejuízo, um número considerável de investigações traz benefícios significativos à população.

Portanto, as pesquisas científicas analisadas acima e a reprodução fictícia, ao menos por ora, de um mundo fundado na biotecnologia e na regulação do corpo e da mente sob aparatos mecânicos e artificiais caminham, de um lado, para o progresso da medicina, mas, de outro, extremamente preocupante, para uma eventual negação da essência humana e, ato contínuo, da própria ideia fundamente de vida humana digna.

Nesse cenário é que se coloca a questão do controle político da biotecnologia. Sobre o assunto, Fukuyama (2003, p. 190-191) salienta a necessidade de superação do debate a partir do extremo libertário - defendido por pesquisadores e cientistas que pretendem fazer recuar as fronteiras da ciência, bem como por setores de mercado, como a indústria biotecnológica, e que "sustenta que a sociedade não deveria e não pode impor limitações ao desenvolvimento de nova tecnologia" -, de um lado, e, de outro, o campo heterogêneo das preocupações morais em relação ao tema, composto por religiosos, ambientalistas, opositores da nova tecnologia e setores da esquerda que se inquietam com a possibilidade de um retorno da eugenia.

Na perspectiva do autor (2003), ambas as abordagens "são equivocadas e irrealistas", na medida em que há tecnologias que, a priori, merecem ser totalmente proibidas, a exemplo da clonagem humana, mas, também, aquelas que necessitam de uma abordagem reguladora mais "nuançada". Nesse sentido, Fukuyama (2003, p. 190) salienta 
que "os países devem regular politicamente o desenvolvimento e o uso da tecnologia" por meio da criação de "instituições que discriminem entre aqueles avanços tecnológicos que promovem o florescimento humano", de um lado e, de outro, "aqueles que representam uma ameaça à dignidade e ao bem-estar humanos." Para o autor, "essas instituições reguladoras devem primeiro ser autorizadas a impor essas discriminações num nível nacional e, por fim, estender seu alcance internacionalmente."

Em síntese, na ótica de Fukuyama (2003), é a comunidade política democraticamente constituída quem deve, no âmbito interno, por meio de seus representantes eleitos, exercer o controle do ritmo e da abrangência do desenvolvimento tecnológico. Sem dúvida que há riscos nessa "delegação", como já se comprovou no presente artigo a partir da experiência nazista, mas são as instituições democráticas, na falta de outra alternativa fidedigna, as responsáveis por capturar a vontade popular de maneira justa e legítima, estabelecendo regulações que atentem, no caso brasileiro, à dignidade da pessoa humana como fundamento da República Federativa brasileira, bem como às Declarações Internacionais de Direitos Humanos comprometidas com a proteção inconteste da vida.

Já no âmbito internacional, o autor (2003) salienta não se trata de criar uma nova organização internacional responsável por esta regulação, tampouco de se implantar uma burocracia não subordinada a poder algum. Trata-se de um projeto passível de concretização a partir da comunhão de esforços dos Estados-nação no sentido de harmonização de suas políticas de regulação - a exemplo do que tem ocorrido no âmbito da União Europeia. Nesse sentido, as ferramentas tradicionais da diplomacia - retórica, persuasão, negociação, influência política e econômica - são fundamentais para a criação de consensos.

\section{CONSIDERAÇÕES FINAIS}

A vida é um direito que exige atenção do poder público e necessita de cuidado pessoal para a sua concreta efetivação. Trata-se do maior direito humano existente, regulado em documentos declarativos e normativos de caráter nacional e internacional e 
caracterizado, enquanto direito da personalidade, como extrapatrimonial, absoluto, irrenunciável, intransmissível, imprescritível, geral, impenhorável e vitalício.

A ideia fundante dos direitos da personalidade, dos quais se inclui a vida, é oportunizar condições básicas para a existência humana. A pretensão é de oferecer, por meio de um sistema jurídico e de políticas públicas, a possibilidade de que todos encontrem realização e felicidade nos âmbitos pessoal e profissional com o amparo do indivíduo, da sociedade e do Estado.

A realização do ser humano perpassa, em tese, pela noção de dignidade da pessoa humana. Isso representa, pelo pensamento kantiano, que o homem deva ser considerado como um fim, e não um meio, em si mesmo, sob pena de sua objetificação e valoração pecuniária. Trata-se, assim, de uma qualidade intrínseca e distintiva do ser humano em relação aos demais seres vivos.

A partir disso, a disposição do corpo humano é regulada pelo Direito, motivo pelo qual não pode ser livremente utilizado pela pessoa para fins que não sejam a sua conquista de dignidade, observando-se as determinações legais. As situações enquadradas em hipótese de violação do corpo natural mediante a intervenção tecnológica chocam-se, por vezes, com mandamentos legais e éticos.

O século $X X$, em regra, permaneceu adstrito a pesquisas médicas pautadas no conhecimento dos mistérios do corpo, mas, surpreendentemente, o século XXI parece estar sendo palco para uma futura criação de vida humana artificial. Essa significativa alteração científica, com possível colisão de interesses, promoveu a criação da bioética e do biodireito, campos de estudos das ciências médicas, jurídicas e éticas.

A discussão acerca de uma eventual artificialização do ser humano com a negação da vida humana e a sua transformação ou mesmo criação em/como objeto da ciência, enquadra-se nos estudos da bioética e do biodireito, promovendo o debate em torno dos benefícios da tecnologia científica para o desenvolvimento sadio e digno da vida da pessoa humana, sem ultrapassar o limite do razoável, do ético e do legal.

As pesquisas científicas, como a criação de vida sintética em laboratório, e a série britânica Black Mirror, com episódios futuristas da inserção de tecnologias no corpo ou mesmo de criação do corpo "(in)humano", suscitam o debate. A ambivalência entre os 
resultados benéficos e maléficos da tecnologia genética para a vida humana exige profunda discussão e atenção, no que a bioética e o biodireito encontram atuação.

O desenvolvimento das pesquisas, as quais têm a tecnologia como alavanca indiscutível, portanto, deve ser contínuo, eficiente e responsável, mas exige-se a observância das normas jurídicas e éticas presentes em documentos nacionais e internacionais, haja vista o pretenso interesse de se alcançar a dignidade e manter, sem sobremaneira artificializá-la, a essência da vida humana natural.

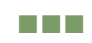

\section{REFERÊNCIAS}

ABBAGNANO, Nicola. Dicionário de filosofia. Tradução de Alfredo Bosi e Ivone Castilho Benedetti. 5. ed. rev. e ampl. São Paulo: Martins Fontes, 2007.

AGAMBEN, Giorgio. Homo sacer: o poder soberano e a vida nua I. Tradução de Henrique Burigo. Belo Horizonte: Editora UFMG, 2007.

AMARAL, Francisco. Direito civil: introdução. 3. ed. Rio de Janeiro: Renovar, 2000.

BARACHO, José Alfredo de Oliveira. Vida humana e ciência. Revista de Direito Constitucional e Internacional, v. 56, p. 113-161, jul./set. 2006. Disponível em: http://www.revistadostribunais.com.br/maf/app/resultList/document?\&src=rl\&srguid=i0a d82d9b00000161fc9a104b51f4e2db\&docguid=I1f9d7100428a11e58548010000000000\&hi

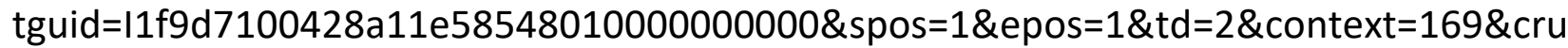
mb-action=append\&crumb-label=Documento\&isDocFG=false\&isFromMultiSumm= \&startChunk=1\&endChunk=1. Acesso em: 07 jan. 2018.

BARROSO, Luís Roberto. O novo direito constitucional brasileiro: contribuições para a construção teórica e prática da jurisdição constitucional no Brasil. Belo Horizonte: Fórum, 2014.

BENATAR, Solomon R. Bioética: poder e injustiça. In. GARRAFA, Volnei; PESSINI, Leo. Bioética: poder e injustiça. São Paulo: Centro Universitário São Camilo; Sociedade Brasileira de Bioética; Edições Loyola, 2003, p. 25-33.

BITTAR, Carlos Alberto. Os direitos da personalidade. 3. ed. Rio de Janeiro: Forense, 1999.

BRASIL. Código Civil e Constituição Federal e legislação complementar: miniobra coletiva de autoria da Editora Saraiva com a colaboração de Luiz Roberto Curia, Livia Céspedes e Juliana Nicoletti. 21. ed. São Paulo: Saraiva, 2015.

CANOTILHO, José Joaquim Gomes. Direito constitucional e teoria da Constituição. 7. ed. Coimbra: Edições Almedina, 2010. 
CÓDIGO de Nuremberg. Nuremberg: [s.n.], 1947. Disponível em: www.fiocruz.br/biosseguranca/Bis/manuais/qualidade/Nurembg.pdf. Acesso em: 22 out. 2018.

COHEN, Claudio. Por que pensar a bioética? Revista da Associação Médica Brasileira, v. 54, n. 6, São Paulo, nov./dez. 2008. Disponível em: http://dx.doi.org/10.1590/S010442302008000600002 . Acesso em: 08 set. 2018.

COUTINHO, Vítor. Artificialização da natureza humana? Biotecnologias à busca de sentido. Humanística e Teologia, tomo 28, p. 151-176. Lisboa: Universidade Católica Portuguesa, 2007. Disponível em: https://repositorio.ucp.pt/bitstream/10400.14/3913/1/ Biotecnologias-A.pdf. Acesso em: 13 maio 2018.

DECLARAÇÃO Americana dos Direitos e Deveres do Homens. Bogotá: [s.n.], 1948. Disponível em: https://www.cidh.oas.org/basicos/portugues/b.Declaracao_ Americana.htm. Acesso em: 14 abr. 2018.

DECLARAÇÃO de Helsinque. Helsinque: [s.n.], 1964. Disponível em: https://www.fcm.unicamp.br/fcm/sites/default/files/declaracao_de_helsinque.pdf. Acesso em: 23 out. 2018.

DECLARAÇÃO Universal dos Direitos Humanos. [S.I.: s.n.], 1948. Disponível em: http://www.ohchr.org/EN/UDHR/Documents/UDHR_Translations/por.pdf. Acesso em: 18 jan. 2017.

DECLARAÇÃO Universal sobre o Genoma Humano e os Direitos Humanos. [S.I.: s.n.], 1997. Disponível em: http://unesdoc.unesco.org/images/0012/001229/122990por.pdf. Acesso em: 08 set. 2018.

DURAND, Guy. Introdução geral à bioética: história, conceitos e instrumentos. Tradução de Nicolás Nyimi Campanário. 2. ed. São Paulo: Loyola, 2007.

FABRIZ, Daury Cesar. Bioética e direitos fundamentais. Belo Horizonte: Mandamentos, 2003.

FIGUEIREDO, Carolina Dantas. Vida artificial e artificialização da vida em Tron. Intexto, Porto Alegre, Universidade Federal do Rio Grande do Sul, n. 27, dez. 2012, p. 200-214. Disponível em: http://seer.ufrgs.br/index.php/intexto/article/view/22987/23495. Acesso em: 13 maio 2018.

FUKUYAMA, Francis. Nosso futuro pós-humano: consequências da revolução da biotecnologia. Rio de Janeiro: Rocco, 2003.

FUNES, Pablo. Evolution of Complexity in Real-World Domains. Tese. The Faculty of the Graduate School of Arts and Sciences, Brandeis University, 2001. Disponível em: http://www.demo.cs.brandeis.edu/papers/funes_phd.pdf. Acesso em: 13 maio 2018.

GARCIA, Maria. Espécie humana, a última fronteira: instrumentalização e ética no uso de embriões humanos. Revista de Direito Constitucional e Internacional, v. 72, p. 258-290, jul./set. 2010. Disponível em: http://www.revistadostribunais.com.br/maf/app/resultList/ document?\&src=rl\&srguid=i0ad82d9b00000161fcb21be09b2a702f\&docguid=17b470c80f2 5511dfab6f010000000000\&hitguid=17b470c80f25511dfab6f010000000000\&spos=1\&epos 
$=1 \& \mathrm{td}=19 \&$ context $=236 \&$ crumb-action=append \&crumb-

label=Documento\&isDocFG=false\&isFromMultiSumm=\&startChunk=1\&endChunk=1.

Acesso em: 10 fev. 2018.

GOZZO, Débora. Diagnóstico pré-implantatório e a busca pela perfeição humana. Revista de Direito Constitucional e Internacional, v. 92, p. 327-352, jul.-set. 2015. Disponível em: http://www.revistadostribunais.com.br/maf/app/resultList/document?\&src=rl\&srguid=i0a d82d9b00000161fca5a8a4bd0ede84\&docguid=If38626304c8311e5bbf7010000000000\&hi tguid=If38626304c8311e5bbf7010000000000\&spos $=2 \&$ epos $=2 \& \mathrm{td}=8 \&$ context $=209 \& \mathrm{crum}$ b-action=append\&crumb-label=Documento\&isDocFG=false\&isFromMultiSumm= \&startChunk=1\&endChunk=1. Acesso em 07 jan. 2018.

HOBBES, Thomas. Leviatã: ou matéria, forma e poder de um Estado eclesiástico e civil. Tradução de Rosina D’Angina. São Paulo: Martin Claret, 2017.

KANT, Immanuel. Fundamentação da metafísica dos costumes. São Paulo: Discurso Editorial e Barcarolla, 2009.

LIMA, Natacha Salomé. Memoria perpetua: comentario del episodio The entire history of you de Black Mirror (2011). Revista Medicina y Cine, 2015, v. 11, n. 3, p. 147-157. Disponível em: http://revistas.usal.es/index.php/medicina_y_cine/article/view /13322/13616. Acesso em: 08 set. 2018.

LOVELOCK, James. Gaia: cura para um planeta doente. São Paulo: Cultrix, 2006.

MARGULIS, Lynn; SAGAN, Dorion. O que é vida? Rio de Janeiro: Jorge Zahar, 2002.

NETFLIX. Black Mirror. 2018. Disponível em: https://www.netflix.com/br/title/70264888. Acesso em: 06 mar. 2018.

NOBRE, Edílson Pereira. O direito brasileiro e o princípio da dignidade da pessoa humana. Revista de Informação Legislativa. Brasília, ano 37, número 145, jan./mar. 2000. Disponível em: https://www2.senado.leg.br/bdsf/bitstream/handle/id/568/r14519.pdf?sequence=4. Acesso em: 08 set. 2018.

OTERO, Paulo. Personalidade e identidade pessoal e genética do ser humano. Coimbra: Almedina, 1999.

PACTO Internacional sobre Direitos Civis e Políticos. [S.I.: s.n.], 1966. Disponível em: http://www.planalto.gov.br/ccivil_03/decreto/1990-1994/D0592.htm. Acesso em: 06 mar. 2018.

PESSINI, Léo; BARCHIFONTAINE, Christian de Paul de. Problemas atuais de bioética. 5. ed.. São Paulo: Centro Universitário São Camilo; Edições Loyola, 2000.

REVISTA SUPERINTERESSANTE. Vida artificial. São Paulo: Abril, 2016. Disponível em: https://super.abril.com.br/ciencia/vida-artificial/. Acesso em: 06 mar. 2018.

RIVABEM, Fernanda Schaefer. Biodireito: uma disciplina autônoma? Revista Bioética, v. 25, n. 02, p. 282-289, maio/ago. 2017. Disponível em: http://revistabioetica.cfm.org.br/index.php/revista_bioetica/article/view/1247/1663. Acesso em: 12 maio 2018. 
ROUSSEAU, Jean-Jacques. O contrato social: princípios do direito político. Tradução de Edson Bini. 2. ed. Bauru: Edipro, 2015.

SARLET, Ingo Wolfgang. Dignidade da pessoa humana e direitos fundamentais na Constituição Federal de 1988. Porto Alegre: Livraria do Advogado, 2001.

SAVULESCU, Julian. The human prejudice and the moral status of enhanced beings: what do we owe the gods? In: SAVULESCU, Julian; BOSTROM, Nick (Org.). Human enhancement. Oxford: Oxford University Press, 2009, p. 211-250.

SILVA, José Afonso. Curso de direito constitucional positivo. 9. ed. São Paulo: Malheiros, 1993. 